\title{
ANALISIS TEMA UNGKAPAN TRADISIONAL BAPENO \\ DI DESA HIANG KECAMATAN SITINJAU LAUT KABUPATEN KERINCI PROVINSI JAMBI
}

\author{
Erwin Gunawan $^{1}$, Ade Rahima ${ }^{2}$, Supriyati ${ }^{3}$ \\ Program Studi Pendidikan Bahasa dan Sastra Indonesia, \\ Fakultas Keguruan dan Ilmu Pendidikan, Universitas Batanghari, \\ Jambi \\ Gunawanerwin888@yahoo.co.id \\ Ade_Rahima@yahoo.com \\ Bunda.zahra34@yahoo.com
}

\begin{abstract}
This research is intended to describe the theme of bapeno traditional expression . the data of this research is words in the traditional expression of bapeno. The data is collected by using observation, interview, recording, and documentation. This research is qualitative descriptive that are analyzed by using sturctural approach and content analysis. This result of the research shows that there are 2 themes found, they are: theme about the relationship of human with human and the relationship of human and God. Those results are acquired from 32 sentences which represent the relationship of human with human and 13 sentences which represent the relationship of human and God.
\end{abstract}

Key Words : theme, traditional expression, bapeno

\footnotetext{
${ }^{1}$ Mahasiswa Program Studi Pendidikan Bahasa dan Sastra Indonesia, Fakultas Keguruan dan Ilmu Pendidikan, Universitas Batanghari, Jambi

${ }^{2}$ Dosen Program Studi Pendidikan Bahasa dan Sastra Indonesia, Fakultas Keguruan dan Ilmu Pendidikan, Universitas Batanghari, Jambi

${ }^{3}$ Dosen Program Studi Pendidikan Bahasa dan Sastra Indonesia, Fakultas Keguruan dan Ilmu Pendidikan, Universitas Batanghari, Jambi
}

Analisis Tema Ungkapan Tradisional Bapeno di Desa Hiang Kecamatan Sitinjau Laut Kabupaten Kerinci Provinsi Jambi 
PENDAHULUAN

Ungkapan tradisional yang ada di Indonesia memiliki kata-kata yang menarik, kata-kata tersebut lahir dari hasil olahan imajinasi manusia dengan realita kehidupan manusia dan lingkungan hidupnya.Ungkapan tradisional biasanya berisi amanahamanah atau pesan-pesan moral yang baik untuk pendengar maupun khalayak ramai. Tetapi tidak semua orang bisa memahami makna dari amanah atau pesan yang disampaikan khususya masyarakat awam karena ungkapan tradisional itu disampaikan dengan katakata yang penuh dengan makna simbolik, seperti dicontohkan Rahima (2014) Cermin gedang nan tidak kabur yang maknanya "Ketentuan yang sudah ada yang berasal dari masa lalu yang terbukti kebenaran dan kebaikannya dalam mengayomi masyarakat diturunkan secara turun temurun".

Dari hasil pengamatan peneliti (09 November 2017), ungkapan tradisional khususnya Kabupaten Kerinci dari satu desa ke desa lain diketahui bahwa ungkapan tradisionalnya berbeda. Desa Hiang merupakan salah satu desa yang berada di Kecamatan Sitinjau Laut, Kabupaten Kerinci Provinsi Jambi. Desa Hiang termasuk desa tertua di Kabupaten Kerinci yang memiliki banyak tradisi yang diturunkan secara turun-temurun dari nenek moyang, salah satu tradisi yang berkembang di desa Hiang adalah bapeno.Bapeno ialah nama suatu ungkapan tradisional yang selalu diadakan dari zaman dahulu hingga sekarang.

Hasil wawancara peneliti dengan Basri Dayah selaku Depati Atur Bumi atau raja segala tokoh adat, bapeno adalah nama tradisi yang berisi do'a padologat atau carologat, penyampaian hajat-hajat atau tujuan dari apa yang kita hendaki, bapeno yang diadakan dalam pernikahan bertujuan untuk menyerahkan mempelai wanita kepada orang adat atau kepada alim ulama, pegawai sarak untuk dilaksanakannya ijab kabul, dan agar kedua mempelai tersebut bisa hidup sejahtera (Hasil wewancara peneliti, 09 November 2017).

Bapeno dilakukan oleh ketua adat atau orang yang dituakan di desa tersebut, dengan sebutan "ninik mamak" dengan belum adanya penelitian yang mengkaji tentang tradisi tersebut, maka banyak masyarakat khususnya remaja tidak mengetahui tentang tema yang ada di dalam ungkapan tradisional bapeno tersebut. Diperkuat dengan hasil wawancara dengan teman sebaya Arya Dinelur yang termasuk ke dalam pemuda karang taruna desa, (09 November 2017) menyatakan bahwa mereka tidak mengetahui apa tema yang terkandung di dalam ungkapan tradisional bapeno tersebut.

Penelitian ini dilakukan dalam upaya untuk mengetahui tema ungkapan tradisional bapeno Desa Hiang, Kecamatan Sitinjau Laut, Kabupaten Kerinci, Provinsi Jambi. Berdasarkan fokus penelitian di atas, maka pertanyaan penelitian ini, "bagaimanakah tema ungkapan tradisional bapeno Desa Hiang Kecamatan Sitinjau Laut, Kabupaten Kerinci, Provinsi Jambi?"

Tujuan dari penelitian ini secara khusus ialah untuk mendeskripsikan tema yang terkandung di dalam Ungkapan Tradisional Bapeno di Desa Hiang, Kecamatan Sitinjau Laut, Kabupaten kerinci, Provinsi Jambi.

Pengertiannya sastra lisan, tradisi lisan dan folklor sering disamakan, sebenarnya ketiga jenis tersebut memiliki pengertian yang berbeda. Sastra lisan ialah bagian dari tradisi lisan, sedangkan tradisi lisan ialah bagian dari folklor, maka dapat disimpulkan folklor merupakan induk dari tradisi lisan dan 
sastra lisan. Untuk memahami perbedaan tiga jenis itu berdasarkan pengertiannya.

Folklor merupakan kebudayaan yang diturunkan secara turun-temurun, folklor tidak hanya dilisankan tapi juga digerakkan, misalnya sebuah tarian yang di wariskan oleh nenek moyang. Danandjaja (2002:2) menjelaskan "Folklor adalah sebagian kebudayaan suatu kolektif, yang tersebar dan diwariskan turun-temurun, diantara kolektif macam apa saja, secara tradisional dalam versi yang berbeda, baik dalam bentuk lisan maupun contoh yang disertai dengan gerak isyarat atau alat bantu pengingat". Folklor tidak hanya berbentuk puisi, melainkan tarian dan kebudayaan yang masih berkembang di masyarakat.

Tradisi lisan bukan hanya berupa suara, melainkan juga dapat berupa kegiatan dan kemudian diikuti tuturan lisan. Sesuai dengan pendapat Sukatman (2009:4) "Tradisi lisan adalah kegiatan, pertunjukkan, dan permainan yang diikuti tuturan lisan, baik masih aktif maupun pasif".

Sastra lisan ialah sastra yang berkembang di masyarakat secara turuntemurun secara lisan. Amir (2013:2) menjelaskan "Bahwa pembicaraan tentang sastra lisan ini bukanlah sesuatu yang baru dikenal oleh masyarakat, melainkan hal ini telah lama ada dan berkembang, hanya saja dengan istilah yang berbeda, misalnya sastra lisan juga dapat dikatakan sastra lama, sastra tradisional, ataupun sastra rakyat".

Folklor memiliki cakupan luas, maka sastra lisan termasuk ke dalam bagian dari folklor. Sesuai dengan diutarakan oleh Amir (2013:164) "Sastra lisan adalah folklor atau bagian dari folklor, khusunya folklor lisan". Karena sastra lisan ini bagian dari folklor, tentunya ciri-ciri sastra lisan juga sama dengan ciri-ciri folklor. Ciri-ciri ini diungkapkan oleh Danandjaja (2002: 34), terdapat 9 ciri yaitu: 1) penyebaran dan pewarisannya dilakukan secara lisan; 2) bersifat tradisional; 3) ada dalam versi-versi atau varian-varian yang berbeda; 4) bersifat anonym; 5) mempunyai pola; 6) mempunyai kegunaan; 7) bersifat pralogis; 8) menjadi milik bersama; 9) bersifat polos.

Bentuk-bentuk sastra lisan ini terdiri atas beberapa macam, Sukatman (2009:6) menyebutkan bentuk-bentuk tersebut seperti : (a) ungkapan tradisional, (b) pertanyaan tradisional, (c) puisi rakyat, (d) cerita prosa rakyat, (e) nyanyian rakyat.

Berdasarkan bentuk-bentuk dari sastra lisan yang telah di uraikan di atas, Bapeno ini termasuk jenis pribahasa. Peribahasa ini terdiri atas beberapa macam, yaitu peribahasa yang sesungguhnya, peribahasa yang tidak lengkap kalimatnya, peribahasa perumpaan, dan ungkapan-ungkapan yang mirip peribahasa. Peribahasa adalah bagian dari jenis puisi lama. Maka bapeno termasuk ke dalam bagian puisi lama.

Puisi berasal dari pemikiran manusia tentang pengalamannya yang dinyatakan dengan menarik dan memberi kesan. Sesuai dengan penjelasan dari Pradopo (2012:7). "Puisi itu mengekspresikan pemikiran yang membangkitkan perasaan, yang merangsang imajinasi panca indera dalam susunan yang berirama. Semua itu merupakan sesuatu yang penting, yang direkam diekspresikan, dinyatakan dengan menarik dan memberi kesan. Puisi itu merupakan rekaman dan interpretasi pengalaman manusia yang penting, diubah dalam wujud yang paling berkesan".

Puisi lama lebih cenderung patuh terhadap aturan. Sesuai dengan pendapat Wahyuni (2014:35) yang mengatakan 
"Puisi lama adalah jenis puisi yang terikat oleh aturan-aturan, diantaranya jumlah baris dalam satu bait, persajakan (rima), banyak suku kata setiap baris, dan irama".

Puisi lama memiliki delapan jenis sesuai dengan pendapat Kosasih (2012:125) "Jenis-jenis tersebut yaitu mantra, pantun, karmina, seloka, gurindam, syair, talibun, peribahasa".

Penelitian yang relevan dengan penelitian ini lain sebagai berikut: 1) Penelitian yang ditulis oleh Ade Rahima, dosen Universitas Batanghari. Jurnal "Jurnal Ilmiah Universitas Batanghari Jambi, vol 17, no 1 (2017); Februari Ji.unbari.ac.id" yang berjudul Interferensi Makna Simbolik Ungkapan Tradisional Seloko Hukum Adat Melayu Jambi Penelitian ini dilakukan pada tahun 2014. 2) Penelitian ditulis oleh Ade Rahima, dosen Universitas Batanghari. Jurnal "Jurnal Ilmiah Universitas Batanghari Jambi, vol 14, no 4 (2014); Desember - Ji.unbari.ac.id" yang berjudul Nilai-nilai Religius Seloko Adat pada Masyarakat Melayu Jambi (Telaah Struktural Hermeuitik). Penelitian ini dilakukan pada tahun 2017. 3) Penelitian yang ditulis oleh Elda Nurfalara, mahasiswa Universitas Jambi. Repository "Bentuk dan Makna Parno dalam Masyarakat Pulau Tengah Kabupaten Kerinci, 2017 - repository.unja.ac.id" yang berjudul Bentuk dan Makna Parno dalam Masyarakat Pulau Tengah Kabupaten Kerinci. Penelitian ini dilakukan pada tahun 2017.

\section{METODE PENELITIAN}

Jenis penelitian merupakan cara kerja suatu penelitian dalam memahami objek yang akan dilaksanakan. Endaswara (2013:8) menyebutkan "Jenis penelitian sastra adalah cara yang dipilih oleh peneliti dengan mempertimbangkan bentuk, isi, dan sifat sastra sebagai subjek kajian". Jenis penelitian sastra digunakan untuk mempermudahkan suatu penelitian khususnya tentang sastra. Jenis penelitian kualitatif ditekankan untuk menggunakan data-data yang empiris untuk memecahkan masalah yang ada. Penelitian kualitatif juga merupakan penelitian yang dilakukan dengan mengutamakan ke dalam penghayatan konsep. Selaras dengan yang dijelaskan Semi (2012:23) "Penelitian kualitatif dilakukan dengan tidak mengutamakan pada angka-angka, tetapi mengutamakan kedalaman pengkhayatan terhadap interaksi antar konsep yang sedang dikaji secara empiris". Penelitian ini menggunakan metode deskriptif. Metode deskriptif menurut Siswantoro (2010:56) "Deskriptif dapat diartikan sebagai prosedur pemecahan masalah yang diselidiki dengan menggambarkan atau melukiskan keadaan subjek atau objek penelitian (novel, drama, cerita pendek, puisi) pada saat sekarang berdasarkan fakta-fakta yang nampak atau sebagaimana adanya". Metode deskriptif ini sangat tepat untuk dijadikan sebagai jenis penelitian khususnya penelitian bersifat kualitatif.

Data yang dikumpulkan untuk penelitian ini, berupa ungkapanungkapan bapeno pada saat acara pernikahan di Desa Hiang Kecamatan Sitinjau Laut Kabupaten Kerinci Provinsi Jambi. Sumber data kualitatif dapat berupa hasil observasi, wawancara, rekam, dokumentasi (Sugiyono, 2016:64). "Data primer adalah data utama yaitu data yang diseleksi atau yang diperoleh langsung dari sumbernya tanpa perantara" (Siswantoro, 2010:70). Data primer dalam penelitian ini adalah data yang peneliti ambil dari hasil wewancara dengan depati atur bumi atau raja segala tokoh adat di Desa Hiang Kecamatan Sitinjau Laut Kabupaten Kerinci. Data sekunder merupakan data penghubung 
yang terdapat di dalam penelitian "Data sekunder adalah data yang diperoleh secara tidak langsung atau melalui perantara, tetapi tetap bersandar kepada kategori atau parameter yang menjadi rujukan" (Siswantoro, 2010:71). Data sekunder dalam penelitian ini merupakan rekaman video maupun buku yang berkaitan dengan ungkapan bapeno.

Teknik pengumpulan data merupakan cara yang digunakan oleh peneliti dalam mendapatkan data. Hal ini selaras dengan Sugiyono (2016:62) yang menyatakan "Teknik pengumpulan data merupakan langkah yang paling strategis dalam penelitian, karena tujuan utama dari penelitian adalah mendapatkan data". Jadi, teknik pengumpuan data ini termasuk bagian penting dalam sebuah penelitian. Langkah kerja yang dilakukan dalam pengumpulan data adalah sebagai berikut a) Observasi adalah melakukan pengamatan untuk memperoleh data secara langsung ke objek penelitian, sehingga dapat melihat dari dekat tentang hal-hal yang menjadi tujuan pengamatan. b) "Wawancara ialah percakapan antara dua pihak, untuk bertukar informasi dan ide melalui Tanya jawab, sehingga dapat dikontruksikan makna dalam suatu topik tertentu" (Esterberg (dalam Sugiyono 2016:72). Wawancara ini peneliti lakukan dengan narasumber yang memahami tentang tradisi bapeno di Desa Hiang, Kecamatan Sitinjau Laut, Kabupaten Kerinci, guna memenuhi sekunder yang peneliti butuhkan. c) Rekam, peneliti melakukan perekaman terhadap ungkapan-ungkapan bapeno yang dilakukan tokoh adat, hal ini dilakukan untuk memperoleh data yang akurat. d) Dokumentasi adalah pengumpulan data dari tempat penelitian, yaitu meliputi buku-buku yang relevan, peraturan-peraturan, laporan kegiatan, foto-foto dan data-data lainnya. Metode dokumentasi biasanya sebagai penunjang metode lain untuk memperoleh data tambahan yang terkait dengan data utama.

setelah data terkumpul, langkah yang dilakukan ialah mengolah data dengan cara mendeskripsikannya. Sesuai dengan pendapat Siswantoro (2010:81) yakni "Teknik analisis yang dilakukan dengan pemaparan dalam bentuk deskriptif terhadap masing-masing data secara fungsional dan rasional". Kegiatan menganalisis data sesuai dengan analisis isi yang dikemukakan oleh Endraswara (2013:162-163) langkah-langkahnya sebagai berikut: 1) peneliti membaca objek kajian secara cermat dan pembacaan secara berulang-ulang; 2) memilih unit-unit yang akan dianalisis sesuai yang akan dikaji peneliti; 3) karena peneliti meneliti ungkapan dan diteliti adalah kalimatnya, maka peneliti meneliti tema yang terdapat dalam ungkapan tradisional bapeno ini; 4) mengelompokkan unit analisis berdasarkan ke lima tema yaitu ketuhanan, kemanusiaan, patriotisme, kedaulatan rakyat dan keadilan social; 5) menganalisis semua data yang berkaitan dengan permasalahan tema terkandung dalam ungkapan tradisional bapeno; 6) membuat kesimpulan dari pertanyaanpertanyaan penelitian.

\section{HASIL DAN PEMBAHASAN}

Berdasarkan data yang dikumpulkan, maka diperoleh hasil dari penelitian ini, yaitu ungkapan tradisional bapeno desa Hiang ini terdiri dari 6 paragraf dan memiliki 45 kalimat. Data ungkapan tradisional bapeno desa Hiang dapat dilihat dari tabel berikut ini. 
Tabel 1. Rekapitulasi Hasil Analisis Tema pada Setiap Paragraf Ungkapan Tradisional Bapeno Desa Hiang Kecamatan Sitinjau Laut Kabupaten Kerinci Provinsi Jambi

\begin{tabular}{|c|c|c|c|}
\hline No & Paragraf & Jumlah Kalimat & Jumlah Tema \\
\hline 1 & Pertama & 4 & 2 \\
\hline 2 & Kedua & 4 & 1 \\
\hline 3 & Ketiga & 7 & 1 \\
\hline 4 & Keempat & 7 & 2 \\
\hline 5 & Kelima & 20 & 2 \\
\hline 6 & Keenam & 3 & 2 \\
\hline
\end{tabular}

Tema merupakan ide maupun gagasan utama di dalam karya sastra.Selaras dengan pendapat Taum (2011:103) “Tema adalah sejumlah ide atau kelompok-kelompok ide yang teratur digunakan dalam penceritaan. Khususnya dalam cerita-cerita bergaya formulaic. Kelompok-kelompok ide itu oleh Lord disebut sebagai themes". Setiap bagian memiliki berbagai macam tema, maka peneliti mengacu kepada pendapat Kosasih (2012:105), yakni tema terbagi menjadi lima macam yaitu ketuhanan, kemanusiaan, patriotisme, kedaulatan rakyat dan keadilan sosial. Penelitian tentang tema ungkapan tradisional bapeno desa Hiang ini, peneliti menggunakan pendapat tersebut dalam menganalisis tema setiap paragrafnya.

Pembahasan yakni proses menganalisis masalah dalam penelitian, pembahasan dalam penelitian ini merupakan penderkripsian tema-tema yang terdapat dalam ungkapan tradisional bapeno Desa Hiang Kecamatan Sitinjau Laut Kabupaten Kerinci Provinsi Jambi. Pada pembahasan ini, peneliti akan menguraikan analisis perparagraf, maka ada enam paragraf yang akan dijelaskan. Dalam setiap paragraph yang dianalisis tersebut, peneliti memberikan penomoran dengan P1-K1 yang artinya adalah P1 ialah paragraf pertama, $\mathrm{K} 1$ ialah kalimat pertama, begitu seterusnya.

Berdasarkan pada hasil penelitian, maka diketahui bahwa pada paragraf pertama, diperoleh dua tema yaitu ketuhanan dan kemanusiaan. Maksud dari tema ketuhanan dalam ungkapan tradisional bapeno desa hiang ini ialah hubungan masyarakat dengan tuhan sedangkan tema kemanusiaan berarti hubungan masyarakat dengan masyarakat. Tema ketuhanan di dalam kalimat ungkapan tradisional bapeno ini berisi tentang hubungan masyarakat berkaitan dengan suatu kepercayaan yang turun temurun dilakukan oleh masyarakat tersebut, yang bertujuan agar keinginan masyarakat dapat dipenuhi oleh Allah Swt. Pada paragraf pertama ungkapan bapeno terkait dengan tema ketuhanan ini dapat dilihat dari keyakinan masyarakat desa hiang yang meyakini bahwa sebuah asap yang berhembus ke tengah acara sebagai tanda penyampaian keinginannya sudah bisa dimulai dan asap tersebut semata-mata untuk mempermudah keinginan masyarakat tersebut terpenuhi, yang terdapat pada kalimat (P1-K2) ialah kok parasap tuh katenguh tando penyampaian hajat dari sepangkalan nuk segerio dimulae. 
Pada paragraf pertama ini terdapat 3 kalimat yang bertemakan kemanusiaan. Maksud dari tema kemanusiaan dalam paragraf ini ialah bahwa masyarakat antaranggota masyarakat erat hubungannya, karena manusia itu ialah makhluk sosial, yang tidak dapat hidup seorang diri. Tema manusia memiliki harkat dan martabat yang sama. Tema kemanusiaan memiliki makna kepedulian antar sesama manusia terdapat dalam kalimat pertama (P1-K1), ketiga (P1-K3), dan keempat (P1-K4). Kalimat-kalimat tersebut erat kaitannya dengan masyarakat, karena inti dari kalimat-kalimat tersebut ialah kepedulian sesama masyarakat seperti pada kalimat P1-K1 kok sarapat kayao nan dudiok kok cawang ahai tando ahai nuk panaeh kok gamiak ahai tando ahai nuk ujian. Maksud dari ungkapan tersebut adalah bahwa masyarakat bersemangat untuk mengisi atau menghadiri acara bapeno karena dalam bermasyarakat antaranggota masyarakat harus saling mengisi karena manusia tidak bisa mencukupi kebutuhanya sendiri tanoa bantuan manusia lain.

Pada paragraf kedua ini hanya terdapat 1 tema yaitu tema kemanusiaan. Tema kemanusian yang terdapat dalam paragraf ini ialah masyarakat yang erat hubungan dengan masyarakat, karena manusia tidak bisa hidup seorang diri, manusia manusia memiliki harkat dan martabat yang sama. Tema kemanusiaan memiliki makna bahwa manusia tidak bisa melakukan semuanya seorang diri sehingga memerlukan bantuan dari sesamanya, terdapat dalam kalimat pertama (P2-K1), dan kedua (P2-K2). Karena inti dari kalimat-kalimat tersebut sama. Seperti pada kalimat P2-K1 asal ayik dari pado hulu asal getoh dari pado batieng asal parago dari sepangkalan, kamai sebagai ninik mamak kok bakatao duliu sapatah kok bajalian duliu salangkah yang manapik si mato parang menentang si mato ahai meniti si ranting matai. Yang dimaksud oleh kalimat tersebut ialah seseorang yang meminta bantuan kepada orang lain yang lebih berpengalaman disemua bidang untuk menyampaiakan keinginan dari orang tersebut. Tema kemanusiaan dalam paragraf ini juga mengandung makna bahwa tidak ada perbedaan antara manusia yaitu manusia memiliki harkat, martabat yang sama, dan saling menghargai satu sama lain. Ditunjukkan di dalam kalimat (P2-K3) dan (P2-K4). Kalimat P2-K3 ialah kok naek diak kamai sebut kan namu kok gediang diak pulao kamai sebut kan gelia yang maksud oleh kalimat tersebut ialah banyaknya masyarakat yang hadir tetapi tidak dibedakan satu sama lain. Kalimat P2-K4 ialah sebelum kantai menyambaikan hajiet uhang laek nak bujunjiong kerjio bupungkao, kepado sarapik kitao nan dudiok yang pertamao kali kantai mintok maaf kepado kantai sarapat nan dudiok kemudian sambutlah salam dari pado kantai menunjukkan bahwa manusia memiliki sifat saling menghargai satu sama lain karena sebelum menyampaian keinginan orang yang bersangkutan meminta maaf terlebih dahulu ke semua masyarakat.

Pada paragraf ketiga ini hanya terdapat 1 tema yaitu tema kemanusiaan. Tema kemanusian yang terdapat dalam paragraf ini ialah bahwa masyarakat erat hubungan dengan anggota masyarakat lain, karena manusia tidak bisa hidup seorang diri dan manusia memiliki harkat dan martabat yang sama sehingga tidak ada perbedaan antara satu dengan yang lainnya. Tema kemanusiaan yang memiliki arti kepedulian antar sesama manusia terdapat di dalam keenam kalimat yang ada diparagraf ketiga yaitu kalimat pertama (P3-K1), kedua (P3-K2), ketiga (P3-K3), keempat (P3-K4), kelima 
(P3-K5), dan keenam (P3-K6). Maka inti dari kalimat-kalimat tersebut sama yakni kepedulian antar masyarakat, seperti P3$\mathrm{K} 2$ yang manao siang ahai tadih lah di bimbia lah di panggaen ngak jioh pun lah kamai layangkan pulao dengan suhat. Maksud dari kutipan tersebut adalah suatu bentuk kepedulian seseorang dengan keinginan seseorang yang berharap agar masyarakat dapat menghadiri acaranya dengan mengirimkan undangan untuk masyarakat tersebut. Tema kemanusiaan dalam paragraf ini memiliki arti bahwa tidak ada perbedaan antara manusia dengan manusia lainya dengan yang ditunjukkan pada kalimat P3-K7 dengan bupu jenieh hatai ngan sucai putih kapaeh dapiat dikelih putih hatai nihlah keadaan kamai puman nyao nih, yang manao hajiet pertamao kali untuk anuk betinu kamai pado malam ahai nih. Arti dari kutipan tersebut adalah dengan kerendahan hati, seseorang memberi tahu bahwa inilah dia yang sebenarnya kepada orang lain dan dia mempunyai keinginan yang ingin disampaikannya. Dengan kerendahan hati, seseorang tersebut memberi tahu bahwa dia sama seperti masyarakat yang lain yang mempunyai keinginan seperti mereka.

Pada paragraf keempat ini diperoleh dua tema yaitu tema ketuhanan dan tema kemanusiaan. Tema ketuhanan di dalam paragraf ini berisi tentang kekuasaan Allah Swt, kemudian tema kemanusiaan di dalam paragraph ini berisi nasehat tentang bahaya hawa nafsu. Tema ketuhanan tidak bisa dihilangkan dari kehidupan sehari hari manusia, karena kekuasaan Tuhanlah yang membuat manusia hidup di dunia ini seperti yang diungkapkan di dalam ungkapan tradisional bapeno ini di dalam kalimat P4-K1 yang manao allah menciptakan makhluk kek dunia nih berpasang-pasangan, adio bumui adio pualao langait adio malam adio pulao siang adio pagui adio pulao petang, adio jantian adio pulao batinao adio gaduih adio pulao anuk bujiang yang manao anuk si a adio pulao nahuh anuk jantian. Ungkapan tersebut berarti bahwa hanya dengan kekuasaan Allah Swt yang menciptakan dunia dan isinya yang berpasang-pasangan sehingga dengan kekuasaannyalah anak si A berjenis kelamin laki-laki. Tema ketuhanan juga merupakan landasan bagi manusia menjalani kehidupan sehari-hari, karena manusia diciptakan didunia ini oleh Allah maka hendaknya manusia juga berbuat seperti apa yang Dia kehendaki. Kalimat P4-K6 mako keduo uhang tuo tadih diak pulao memisahkan adiat dengian lembagio, lah tau adiat dan negehui negehui bubagi adiat adiat bubagi sarak sarak berkiat kitabullah menjelaskan bahwa kedua orang tua tidak pernah memisahkan kehidupan dunia dengan agama yang tuntut dengan mengikuti ajaran Allah Swt yang ditunjukkan dalam Al-Qur'an.

Tema kemanusian dalam paragraf ini yaitu tentang bahaya hawa nafsu. Hawa nafsu sesat akan membuat diri manusia kotor, sehingga banyak masyarakat yang tidak menginginkan itu terjadi, sehingga cara mengantisipasi hal tersebut agar tidak terjadi, maka masyarakat mengigatkan hal tersebut dengan penyampaian-penyampaian yang halus seperti dalam kalimat paragraph ini dan ketika anggota masyarakat yang sudah siap untuk menikah, maka dia berterus terang kepada keluarganya agar terhindar dari hawa nafsu yang kotor. Kalimat yang menjelaskan bahwa menahan hawa nafsu sangat dianjurkan agar manusia terkendali dengan baik sehingga tidak merugikan dirinya maupun orang lain hal tersebut juga ditunjunkkan dalam kedua kalimat (P4$\mathrm{K} 2)$, dan (P4-K3), kedua kalimat tersebut 
intinya sama seperti dalam kalimat P4-

K2 manao anuk jantian tuh samao pulao dengen ima panunggu tanjaong kurang hati-hati ternuk uhang pulao ngak dimakien, kemudian kelih pulao kerinuh kok punggung utan pulao lah panaeh pado adet lah pataut nian berumuh tanggao puman nyao tuh. Yang dimaksud oleh kalimat tersebut bahwa seorang laki-laki dituntut untuk menahan hawa nafsunya jika tidak, maka dia bisa berbuat hal yang tidak diinginkan oleh masyarakat, dia adalah seseorang yang sudah siap lahir dan bathin untuk menjadi kepala keluarga. Manusia memiliki rasa bahwa sudah layakkah dia untuk berumah tangga agar tidak merugikan dirinya dan keluarganya maupun orang lain, maka manusia dituntut untuk berterus terang kepada keluarganya agar hal yang tidak diinginkan tidak terjadi seperti hal tersebut dijelaskan di dalam paragraph ini kalimat keempat (P4-K4), keenam (P4-K6), dan ketujuh (P4-K7). Karena kalimat-kalimat ini intinya sama seperti kalimat P4-K6 anuk bantinu jantian lah punyao pulao taganui mako keduo pihak tagui tadih, yang dilalui oleh ninik mamak kok bajalian dului salangkah, yang manapik si mato parang menentang si mato ahai meniti si ranting matai untuk menjodohkan uhang nih beduio. Maksud dari ungkapan tersebut adalah bahwa seorang anak perempuan yang sudah siap untuk menjadi ibu rumah tangga memberi tahu kepada keluarganya yang lebih mengerti untuk menanyakan kepada seorang anak laki-laki yang sudah siap untuk menjadi kepala keluarga agar mereka dapat dijodohkan sehingga keluarga mereka bersepakat untuk menyatukan mereka berdua.

Pada paragraf kelima diperoleh enam tema ketuhanan dan 14 tema kemanusiaan. Tema ketuhanan dalam paragraf kelima ungkapan tradisional bapeno desa hiang ini maksud ungkapan tersebut ialah bahwa hubungan masyarakat dengan tuhan sedangkan tema kemanusiaan berarti hubungan masyarakat dengan masyarakat. Tema ketuhanan dalam paragraf ini berisi tentang hubungan manusia dengan tuhan dalam mencari rezeki yang halal yang diperbolehkan oleh Allah Swt yang dicari dijalan yang benar atau tidak sesat yang diungkapkan dalam kalimat P5-K5 kemudian tuh pulao kok nyao duwio nih dalem mengarungi umuh tanggao kok umur nasai agui Seumur jagiong kok dahoh agui sarupik pinang, supayao keduo uhang tuo nyao tuh untuk memapah memimbin mudah-mudahan nalok rizki pegoi pagui balek petang rizki ngak halal lao puman nyao tuh. Ungkapan tersebut berarti bahwa karena mereka baru ingin menjalani kehidupan rumah tangga, maka banyak sekali cobaan yang akan dilalui sehingga masyarakat berharap kepada orang tua mereka untuk membimbing dan mengarahkan mereka agar mencari rezeki halal yang diperbolehkan agama. Tema ketuhanan juga tidak bisa dipisahkan darii kehidupan sehari-hari, dan manusia dituntut untuk selalu mengigat Allah Swt dalam setiap kondisi apapun seperti kalimat yang diungkapkan di dalam ungkapan tradisional bapeno desa hiang (P5-K6) dan (P5-K16) yang intinya sama-sama untuk mengingat Allah. Kalimat P5-K6 mudah-mudahan apo ngak diusaho supayo dapiat berkembang biok apo ngak di tanam lekaeh tumbaoh dan diak pulao melupao allahutakala puman tuh. Maksud ungkapan tersebut adalah bahwa masyarakat berharap apa yang mereka peroleh dari hasil jerih payahnya tidak pernah melupakan Allah Swt karena Allah yang memberi segalanya. Tema ketuhanan juga menyangkut kepercayaan adat yang dilakukan turun temurun. Hal tersebut semata-mata sebagai tanda bahwa 
mereka bukan hanya sekedar berjanji maupun meletakkan tanda bahwa mereka sah menjadi suami istri kepada masyarakat tetapi mereka juga harus berjanji kepada adat dan kepala Allah Swt yang maha mengetahui, seperti dalam kalimat P5-K8 yang manao pado malam nih untuk meletakkan tando jadi tanto tetap, yang manao tando jadi tetap nyao tuh yaitu hajiet lamao pusako usang, yang manao hajiet lamao tuh sihaeh ngan sarmpaun kok ukaok ngan sabatiang sebagai tando. Kemudian tema ketuhanan ini juga berkaitan dengan kepercayaan masyarakat yang dilakukan secara turun temurun semata-mata agar do'a yang diharapkan terkabul seperti yang etrdapat di dalam kalimat P5-K17 kemudian tuh pulao di tengah ka pulao kamiyan dan alakadar yang manao hajiet pertamao kali untuk mendoakan supayao berkiat penganten nih. Ungkapan tersebut bermaksud bahwa diletakkan kemenyan dan uang yang merupakan kepercayaan masyarakat agar do'a yang diharapkan terkabul, kemudian mereka berdo'a agar pengantin tersbeut diberikan keberkahan. Tema ketuhanan juga berkaitan dengan keinginan masyarakat yang disampaikan melalui do'a seperti yang ada di dalam kalimat (P5-K18), (P5-K19), dan (P5-K20). Inti dari kalimat-kalimat tersebut sama, yaitu untuk mendo'akan agar arwah manusia yang telah meninggal mendapat rahmat kubur dan agar masyarakat tidak mendapatkan musibah karena Allahlah yang mengatur segalanya. Kalimat P5K18 kemudian nulung arwah mati lamao mati bahiu kok sempait kubu supayao dilapang kok hangat supayo sejuk satau rahmat kubio hendaknyao man tuh. Maksud dari kutipan tersebut adalah masyarakat juga berdo'a meminta kepada Allah supaya arwah manusia yang sudah meninggal mendapatkan rahmat kubur seperti yang diinginkan semua orang.
Tema kemanusian dalam bagian ini berkaitan dengna kepedulian antar sesama manusia, saling bergotong royong membantu satu sama lain. Seperti yang disebutkan di dalam ungkapan tradisional bapeno desa hiang pada kalimat (P5-K1), kalimat (P5-K7), dan kalimat (P5-K10). Inti dari kalimat (P5-K1) dan (P5-K7) tersebut sama seperti P5-K1 mako pado malam ahai nih gimba sarapat kitao ngan hadir terutamao anggota negehui untuk menunjaok membagih tau bahwo malam nih uhang nih melaksanakan akad nikah. Inti dari ungkapan tersebut adalah masyarakat meluangkan waktu hanya untuk mengisi acara peresmian pernikahan masyarakat lainnya. Tema bahwa manusia saling mengisi satu sama lainnya yang dilihat dari sifat saling membantu terlihat pada kalimat P5-K10 kemudian dari pado tuh kaen ngan sagalumbiun kok umu uhang nuk nguku pematang, kok ladieng uhang nuk nebeh kemudian uhang nih nuk samao sakatao sailae samudek. Maksud kutipan tersebut adalah bahwa setelah semua masyarakat bersama-sama membantu dalam mempersiapkan sebuah acara, masyarakat hanya berharap agar mereka selalu bersama selamanya. Masyarakat membantu dalam mempersiapkan acara tersebut. Tema kemanusiaan di dalam paragraph ini juga berisi tentang nasehat manusia dengan manusia lain untuk menjalin rumah tangga bahagia seperti yang masyarakat inginkan, seperti terlihat pada kalimat ketiga (P5-K3), keempat (P5-K4), kesembilan (P5-K9), kesebelas (P5-K11), kedua belas (P5-K12), ketiga belas (P5-K13), dan keempat belas (P5K14). Kalimat-kalimat tersebut erat kaitannya dengan masyarakat. Inti kalimat tersebut sama berkaitan erat denga kepedulian seperti kalimat P5-K3 kemudian tuh pulao kok setelah nyao melaksanakan akad nikah supayo nyao duwio nih sa iyao sakatao kok kadateh 
samu-samu mendapiat angain kok kabawiah samu-samu mendapiat ayaek. Maksud dari ungkapan tersebut adalah bahwa masyarakat berharap setelah mereka menjadi suami istri mereka berdua bisa bersama-sama mencari rezeki. Bentuk kepedulian msyarakat ialah memberikan nasehat agar mereka tetap bersama.

Pada paragraf keenam ini diperoleh dua tema yaitu tema ketuhanan dan tema kemanusiaan. Tema ketuhanan di dalam paragraf ini berisi permintaan kepada Yang maha kuasa supaya apa yang didoakan oleh masyarakat terkabul dan permintaan ampunan kepada Allah Swt, sedangkan tema kemanusiaan dalam paragraf ini berisikan tentang permintaan maaf kepada masyarakat sebagai tanda sikap saling menghargai antara manusia kemanusia lainnya. Umat manusia tentu tidak luput dari kesalahan dan dosa kepada Allah Swt, tetapi Allah maha pengampun lagi maha penyayang, dan maha pemberi apa yang kita inginkan. Sehingga manusia dituntut untuk berdo'a dan meminta ampunan atas kesalahan yang telah dia perbuat seperti dalam kalimat (P6-K1) dan (P6-K2). Inti dari ungkapan tersebut hampir sama P6-K1 tuh lah pokok-pokok penyampaian hajiet pado malam ahai nih dari sepangkalan semoga hajiet tesebiut dapiat diterima Allah Swt. Bentuk keinginan masyarakat kepada Allah Swt agar do'a mereka terkandung di dalam ungkapan tradisional bapeno desa Hiang ialah 45 kalimat. b) Tema-tema yang terdapat dalam 6 paragraf ungkapan tradisional bapeno desa Hiang tersebut adalah paragraf pertama bertema tentang ketuhanan dan kemanusiaan. Paragraf kedua bertema tentang kemanusiaan. Paragraf ketiga bertema tentang kemanusiaan. Paragraf ke empat bertemakan tentang ketuhanan dan kemanusiaan. Paragraf kelima didengar dan dikabulkan. Serta kalimat P6-K2 kemudian tuh pulao daliem penyampaian terdapiat kesalahan kehilafan salah pado Allah mintak ampunan. Maksud ungkapan tersebut adalah ketika di dalam penyampaian sebuah keinginan, manusia terdapat kekhilafan maupun kesalahan maka mereka meminta ampunan kepada Allah Swt karena Allah adalah sang pencipta yang maha pengampun. Tema kemanusiaan dalam paragraf ini ialah tanda saling menghargai di dalam masyarakat yang ditunjukkan di dalam kalimat P6-K3 salah pado sarapat kitao ngak hadir kantai mohon maaf untuk memajiang belipia kitao serah pulao pado mangkau ngan lain. Maksud ungkapan tersebut adalah bahwa acara meminta maaf kepada masyarakat yang hadir karena manusia tidak luput dari kesalahan, selain itu orang yang mempunyai tersebut memberi kesempatan kepada masyarakat lain untuk menambahkan masukan maupun saran.

\section{SIMPULAN}

Berdasarkan hasil pembahasan yang telah duraikan, dalam ungkapan tradisional bapeno desa Hiang ini terdiri atas 6 paragraf, maka kesimpulan dalam penelitian ini adalah sebagai berikut: a) Jumlah kalimat yang

bertemakan ketuhanan dan kemanusiaan. Paragraf keenam bertemakan tentang ketuhanan dan kemanusiaan.

Berdasarkan uraian di atas dapat disimpulkan bahwa ungkapan tradisional bapeno desa Hiang ini cenderung mengandung tema kemanusiaan, karena setiap paragraf mempunyai tema tentang kemanusiaan. Tema kemanusiaan berarti kalimat-kalimat dalam ungkapan tradisional bapeno desa Hiang cenderung 
menunjukkan kepedulian masyarakat terthadap sesama manusia.

\section{DAFTAR PUSTAKA}

Amir, Adriyetti. (2013). Sastra Lisan Indonesia. Yogyakarta: Penerbit Andi.

Danandjaja, James. (2002). Folklor Indonesia Ilmu Gosip, Dongeng, dan lain-lain. Jakarta: Pustaka Utama Grafitri.

Endraswara, Suwardi. (2013). Metodologi Penelitian Sastra. Yogyakarta: Center For Academic Publishing Service (CAPS).

Kosasih, E. 2012.Dasar-dasar Keterampilan Bersastra. Bandung: Yrama Widya.

Pradopo, Rachmat Djoko. 2012. Pengkajian Puisi. Yogyakarta: Gadjah Mada University Press.

Rahima, Ade 2014.Nilai-nilai Religius Seloko Adat Pada Masyarakat Melayu Jambi (Telaah Struktural Hermeneutik). Jurnal Ilmiah Universitas Batanghari Jambi, volume 14 nomor 4 tahun 2014. http://ji.unbari.ac.id/index.php/ilmi ah/article/viewFile/215/211
Rahima, Ade 2017.Interpretasi Makna simbolik UngkapanTradisional Seloko Hukum Adat Melayu Jambi. Jurnal Ilmiah Universitas Batanghari Jambi, volume 17 nomor 1 tahun 2017. http://ji.unbari.ac.id/index.php/ilmi ah/article/download/240/234.

Semi, M Atar. (2012) Metode Penelitian Sastra. Bandung: Angkasa

Siswantoro. (2010). Metode Penelitian Sastra: Analisis Struktur Puisi. Yogyakarta: Pustaka Pelajar

Sugiyono. (2016). Memahami Penelitian Kualitatif. Bandung: Alfabeta

Sukatman. (2009). Butir-butir Tradisi Lisan Indonesia Pengantar Teori dan Pembelajarannya. Yogyakarta:LakBang PRESSindo Yogyakarta.

Taum, Yoseph Yapi. (2011). Studi Sastra Lisan; Sejarah, Teori, Metode dan Pendekatan Disertai Contoh Penerapannya. Yogyakarta: Lamalera.

Wahyuni, Ristri. (2014). Kitab Lengkap Puisi, Prosa, dan Pantun Lama. Jogjakarta: Saufa. 